\title{
A POLÍTICA PÚBLICA DE ECONOMIA CRIATIVA E SOLIDÁRIA DO MUNICÍPIO DE ARARAQUARA/SP'
}

Camila Capacle Paiva ${ }^{2}$

Edinho Silva ${ }^{3}$

\section{INTRODUÇÃO}

O município de Araraquara, conhecido como a Morada do Sol, é também a morada da solidariedade. $\mathrm{Na}$ implementação de uma gestão democrática e participativa da prefeitura municipal (2017-2020), as inclusôes social e produtiva se configuram como eixo central, e se destacam nas açóes voltadas para geração de trabalho e renda - na perspectiva da economia criativa e solidária -, visando à organização da população socialmente vulnerável e à geração de oportunidades para a garantia de direitos fundamentais.

Araraquara é um município da região central do interior do estado de São Paulo, com estimativa de 236.072 habitantes. O Índice de Desenvolvimento Humano Municipal (IDH-M) é de 0,815 , classificado como o $14^{\circ}$ maior do Brasil e considerado elevado pelo Programa das Naçóes Unidas para o Desenvolvimento (PNUD). Foi a cidade brasileira mais bem qualificada quanto ao Índice Firjan de Desenvolvimento Municipal em 2007, ${ }^{4}$ que utiliza critérios de renda, educação e saúde para sua avaliação. Com importantes indústrias, empresas e universidades, o município se destaca com uma economia dinâmica.

Todavia, Araraquara não é uma ilha e também é atingida pelo aumento dos índices de pobreza e desemprego do Brasil. Conforme demonstram os dados de 2019, ${ }^{5}$ o município possui 12.686 famílias inscritas no Cadastro Único para Programas Sociais, sendo que cerca de 50\% delas possuem renda per capita mensal de até $25 \%$ do salário mínimo e composição familiar majoritária de mulheres responsáveis economicamente por suas famílias.

Diante do cenário de agravamento da pobreza e do desemprego, a economia solidária se apresenta como uma estratégia de desenvolvimento local sustentável, que objetiva desenvolver o território e fortalecer a comunidade, criar uma rede colaborativa, valorizar a cultura e os saberes locais, e possibilitar práticas coletivas e sistêmicas que gerem trabalho, renda e melhorias na vida dos cidadãos. ${ }^{6}$

A política pública de economia solidária no município, que começou a ser desenhada em 2001, atualmente assume um papel importante na promoção de programas e açôes que

1. DOI: http://dx.doi.org/10.38116/bmt70/economiasolidaria1

2. Coordenadora-executiva do Trabalho e de Economia Criativa e Solidária da Prefeitura Municipal de Araraquara. E-mails: <ecosolidaria@ araraquara.sp.gov.br> e <camila.capacle@gmail.com>.

3. Prefeito municipal de Araraquara. E-mails: <prefeitomunicipal@araraquara.sp.gov.br> e <edinhoararaquara@icloud.com>.

4. Edição 2014, ano-base 2007. Disponível em: <https://tinyurl.com/y52vaqew>.

5. Ver mais informações em Strozzi (2019).

6. Para uma análise da dinâmica ecossistêmica da economia solidária em Araraquara, ver Sanches e Morais (2020) e Morais e Bacic (2020). 
buscam a inclusão social e produtiva, o combate à fome e o resgate da cidadania, por meio da geração de renda, de forma coletiva e participativa.

Este texto mostra a trajetória de construção da política pública de economia solidária em Araraquara desde o surgimento na agenda de governo até a estrutura atual, incluindo programas, projetos, açóes, orçamentos, equipes técnicas e um modelo de gestão participativa que prioriza o protagonismo social, a intersetorialidade e a integração entre as múltiplas açôes da coordenadoria.

\section{SURGIMENTO DA ECONOMIA SOLIDÁRIA NA AGENDA DE GOVERNO}

A economia solidária desponta como estratégia de organização social e de geração de renda desde a primeira gestáo do Partido dos Trabalhadores (PT), no período 2001-2004, em Araraquara, quando foi criada, na estrutura da Secretaria Municipal de Desenvolvimento Econômico (SDE), uma pasta de gestão de projetos em geração de trabalho e renda. Em consonância com as políticas que estavam sendo desenvolvidas em outras prefeituras, Araraquara esteve entre as pioneiras nesse processo, não apenas no estado de São Paulo, mas também em nível nacional.7

Havia um esforço de agentes políticos e apoiadores desde 1998 para organizar os catadores de material reciclável que trabalhavam no lixão do município. Em 2001, uma das primeiras iniciativas do Poder Executivo foi organizar esses catadores e passar-lhes parte da operação do centro de triagem. Em novembro de 2001, 31 catadores começaram a trabalhar de forma coletiva, por meio da formalização da Associaçáo Acácia de Trabalhadores de Materiais Reaproveitáveis de Araraquara. ${ }^{8}$ Em 2003, mudanças significativas no poder público iniciaram um novo processo na associação: o Departamento Autônomo de Água e Esgotos (DAAE) de Araraquara assumiu o tratamento e a destinação final dos resíduos sólidos do município, o lixão foi transformado em aterro sanitário controlado e a Associação Acácia dos Trabalhadores de Materiais Reaproveitáveis de Araraquara assumiu a operação das atividades da usina de triagem.

Ainda durante o período 2001-2004, foi criado um projeto-piloto de coleta seletiva em dois bairros da cidade, além da organização de uma associação dos ambulantes de alimentos e uma cooperativa de costura com mulheres que estavam recém-desempregadas da indústria têxtil.

No início de 2005, no segundo mandato (2005-2008), a política pública de economia solidária ganhou seu lugar institucional como Coordenadoria Executiva de Economia Social e Solidária (CESS), pertencente à estrutura da SDE, e passou a compor, no seu quadro, o Posto de Atendimento ao Trabalhador (PAT) e o Banco do Povo Paulista, ambos programas do governo estadual, em parceria com o município.

Durante o período 2005-2008, foi estruturado um programa municipal de economia solidária e formaram-se novos empreendimentos com o fomento da política pública de economia solidária, tais como: Associação Mãos que Criam, voltada para o artesanato; Associação de Mulheres Assentadas do Assentamento Monte Alegre Seis (AMA), com foco

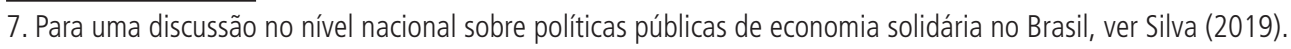

8. Para uma discussão no nível nacional sobre o trabalho dos catadores de material reciclável no Brasil e as principais políticas de apoio a esses trabalhadores, ver Silva (2017b). 
para a alimentação e a agricultura familiar; Associação dos Trabalhadores do Comércio Alternativo de Araraquara (ATCAAR); Cooperativa de Costura de Araraquara (Costuara); Estamparia da Juventude; entre outros pequenos coletivos que começavam a se formar. O conjunto de poder público, universidade e empreendimentos solidários criou o Fórum Municipal de Economia Solidária e a Feira de Economia Solidária ${ }^{9}$ - na qual havia o clube de trocas -, que ocorria mensalmente em uma praça no centro comercial da cidade.

Em 2005, a Associação Acácia dos Trabalhadores de Materiais Reaproveitáveis foi transformada em Cooperativa Acácia de Catadores, Coleta, Triagem e Beneficiamento de Materiais Recicláveis (Cooperativa Acácia), ${ }^{10}$ com a implantação do programa Coleta Seletiva de Araraquara, que em 2007 expandiu sua abrangência com coleta porta a porta para 100\% da área urbana do município. Um dos primeiros casos no Brasil, o município de Araraquara, por meio do DAAE, contratou tal cooperativa para a prestação do serviço de coleta, triagem e beneficiamento de materiais recicláveis, com dispensa de licitação por meio da Lei no 11.455 , que havia sido promulgada em janeiro de 2007, estabelecendo diretrizes nacionais para o saneamento básico. ${ }^{11}$ No art. 57, essa lei alterava o art. 24, inciso XXVII, da Lei no 8.666, sobre licitaçóes públicas e abria espaço para a contratação de cooperativas de catadores (Brasil, 2007).

Ao final de 2008, além de um programa sólido de coleta seletiva na cidade, podemos destacar algumas importantes conquistas para a política pública de economia solidária. A prefeitura municipal inaugurou uma padaria e uma cozinha solidárias no Assentamento Monte Alegre, demanda aprovada na plenária temática das Mulheres, do Orçamento Participativo. A padaria virou a sede da AMA e um espaço de renda feminino no centro do assentamento; em pouco tempo, ganhou dos ciclistas o nome de Padoka e foi protagonista no desenvolvimento do turismo rural - rota de ciclistas e no circuito dos sabores.

A prefeitura municipal inaugurou também um ateliê de costura para mulheres que se organizaram por meio de capacitação no Fundo Social de Solidariedade e, junto ao ateliê, a Estamparia da Juventude, demanda do Orçamento Participativo (plenária da Juventude). Ambos os empreendimentos foram estabelecidos em parceria com uma organização da sociedade civil (OSC).

Por fim, por meio da política pública de economia solidária, foi construída e inaugurada uma loja solidária no Terminal Central de Integração de transporte público, local com grande movimentação de pessoas. A loja solidária passou a ser o espaço coletivo de vendas dos diversos grupos existentes.

A construção de uma política pública para além de um programa de governo possibilitou que a economia solidária permanecesse com uma estrutura, ainda que tímida, durante os oito anos seguintes de governo (2009-2012/2013-2016). A estrutura institucional passou a ser a Gerência de Economia Social e Solidária, vinculada à Coordenadoria Executiva de Geração de

9. Feira de economia solidária realizada na praça Santa Cruz durante 2007 e 2008 em Araraquara.

10. Para conhecer na íntegra o trabalho da Cooperativa Acácia e o programa Coleta Seletiva de Araraquara, ver Paiva (2016; 2017).

11. Esse histórico pode ser encontrado em MNCR (2019). 
Trabalho e Renda da Secretaria Municipal de Ciência, Tecnologia, Turismo e Desenvolvimento Sustentável. Os empreendimentos mais bem estruturados permaneceram ativos, como a Cooperativa Acácia, a AMA e a Associação Mãos que Criam, preservando, assim, o contrato de coleta seletiva, a Padoka e a loja solidária, respectivamente.

\section{POLÍTICA PÚBLICA DE ECONOMIA CRIATIVA E SOLIDÁRIA}

No programa de governo elaborado para 2017-2020, a economia solidária aparece em diversas açôes transversais, para além do desenvolvimento econômico e sustentável, dialogando com políticas das áreas de desenvolvimento rural, direitos humanos, mulheres, igualdade racial, diversidade sexual, juventude, pessoa com deficiência, população em situaçáo de rua, cultura, saúde e educação.

Em 2017, iniciou-se a gestão da Prefeitura de Araraquara: cidade solidária e participativa (2017-2020), com a criação da Coordenadoria Executiva de Trabalho e de Economia Criativa e Solidária (Cetecs), alocada na Secretaria Municipal do Trabalho e do Desenvolvimento Econômico (SMTDE). A economia solidária ganhou novo fôlego como uma pauta estratégica para a política de desenvolvimento econômico e social, o combate à fome e a inclusão social e produtiva de pessoas e famílias em situação de alta vulnerabilidade social.

Por meio de um diagnóstico socioeconômico, a prefeitura de Araraquara detectou seis regiôes de maior vulnerabilidade social da cidade, denominados territórios: Cecap/Residencial dos Oitis; Jardim Cruzeiro do Sul; Jardim das Hortênsias; Parque São Paulo; Jardim São Rafael; e Valle Verde. Nesse contexto, em 2018, foi lançado o Programa Municipal Territórios em Rede, por meio da Lei no 9.344/2018, coordenado pela Secretaria Municipal de Assistência e Desenvolvimento Social (SMADS) e executado de forma intersetorial, cujo objetivo é a proteção social e a prestaçáo de serviços integrados e direcionados à satisfaçáo das necessidades vivenciadas pelos indivíduos e famílias em territórios prioritários (Araraquara, 2018a). O programa possui quatro eixos de atuação: mobilização, articulação, formação e desenvolvimento territorial. Por meio de comitês locais e fóruns regionais, os gestores públicos e entidades se articulam para o desenvolvimento de estratégias, ações e projetos.

O Programa Municipal Territórios em Rede é um norte de atuação para o desenvolvimento das políticas sociais no município. Na política pública de geração de trabalho e renda, foram desenvolvidas algumas açóes territoriais, com destaque para oficinas de sensibilização em economia solidária, realizadas nos Centros de Referência de Assistência Social (Cras), e as feiras do território, com objetivo de desenvolvimento dos saberes locais.

Além da atuação territorial, a política pública de economia solidária assumiu como prioridade as pessoas com alta vulnerabilidade social, que, em geral, possuem baixa escolaridade, pouca experiência profissional e, em sua maioria, são negros(as) e mulheres responsáveis economicamente por suas famílias. De modo recorrente, juntam-se às outras vulnerabilidades como o alcoolismo e a drogadição, a violência doméstica, as condiçôes de moradia ou a situação de rua, a falta de vínculos afetivos etc. 
A porta de entrada é a inclusão social, a garantia de direitos e de alimentação adequada, e o resgate da cidadania. A qualificação profissional está atrelada ao processo de fortalecimento desses indivíduos, de (re)conhecimento dos seus direitos, de promoção de uma cultura de paz e comunicação não violenta. Para além de profissóes, busca-se que, ao longo do processo de reinserção individual, seja feita a construção de coletivos. Propomos que a inclusão produtiva seja realizada por meio da economia solidária, seguindo os princípios da autogestão, da cooperação e da solidariedade. Ao final do processo, apresentamos a organizaçáo produtiva coletiva como uma porta de saída.

Fruto desse processo, a Cetecs conseguiu encaminhar alguns beneficiários ao mercado de trabalho formal, fomentar empreendedores que se formalizaram como microempreendedor individual (MEI), acessaram crédito e passaram a empreender e, principalmente, a desenvolver o projeto O Cooperativismo como Porta para o Futuro, que apoiou a formação de quatro cooperativas de trabalhos com beneficiários dos programas sociais. ${ }^{12}$

\subsection{Programas e ações da economia solidária}

\subsubsection{Programa Municipal de Inclusão Social e Cidadania}

É a principal porta de entrada para as açóes de economia solidária em Araraquara. Voltado para capacitação e qualificaçáo profissional de pessoas de baixa renda, o município possui o Espaço Kaparaó, que é um centro de capacitação social e profissional, onde são oferecidos cursos profissionalizantes gratuitos, realizados com recursos próprios do município ou parcerias com o Sistema $S^{13}$ e universidades locais. Dois programas de transferência de renda e combate à fome, vinculados à SMADS, são executados em parceria com a Cetecs: o Programa de Incentivo à Inclusão Social (PIIS) e o Programa Municipal de Combate à Fome e Incentivo à Inclusão Produtiva, o Bolsa Cidadania.

O PIIS, criado pela Lei no 8.998/2017, tem como objetivo propiciar a inclusão social, a qualificação profissional, a elevação da escolaridade e a renda para munícipes em situação de vulnerabilidade social, por meio da concessão de bolsa auxílio qualificação no valor mensal de um salário mínimo, pelo período de um ano, podendo ser prorrogado por mais um ano (Araraquara, 2017a). A bolsa tem como condicionalidade a participação, com frequência igual ou superior a 75\%, nos cursos de capacitação profissional e na educação básica. Os beneficiários do PIIS participam, no período da tarde, do Núcleo de Educação para Jovens e Adultos (Neja) e, no período da manhã, de programa anual de qualificação profissional no Espaço Kaparaó,

12. Foram formalizadas quatro novas cooperativas com apoio da Cetecs no primeiro semestre de 2020: Cooperativa de Trabalho em Serviços Gerais - Vitória Multiserviços; Cooperativa de Trabalho e Serviços de Alimentação Panelas Unidas; Cooperativa dos Trabalhadores da Construção Civil de Araraquara - Coopermorada; e Cooperativa Social de Trabalho em Recuperação de Materiais dos Egressos Prisionais de Araraquara Sol Nascente.

13. O Sistema S é o nome pelo qual ficou convencionado de se chamar o conjunto de nove instituições de interesse de categorias profissionais, estabelecidas pela Constituição Federal de 1988. Citam-se três como exemplos: o Serviço Nacional de Aprendizagem Comercial (Senac), o Serviço Brasileiro de Apoio às Micro e Pequenas Empresas (Sebrae) e o Serviço Nacional de Aprendizagem Industrial (Senai). 
onde aprendem diversas atividades, tais como: fazer um currículo e participar de uma entrevista de emprego; informática básica; cultura de paz; marketing pessoal; e cursos profissionalizantes, como auxiliar administrativo, vendas, zeladoria, limpeza, jardinagem, pintura, estética e beleza, alimentação, entre outros. Os beneficiários também aprendem módulos específicos sobre empreendedorismo e economia solidária de modo que terminam o ciclo aptos a participar dos empreendimentos econômicos solidários (EES).

O Programa Municipal de Combate à Fome e Incentivo à Inclusão Produtiva, o Bolsa Cidadania, criado pela Lei no 9.585/2019, visa garantir o direito à renda mínima para o combate à fome e também a inclusão produtiva como porta de acesso à cidadania (Araraquara, 2019b). O programa é destinado às pessoas ou às famílias que se encontram em situação de extrema vulnerabilidade social e/ou de extremo risco social. As pessoas ou as famílias, quando inseridas no programa, recebem um vale-alimentação ${ }^{14}$ e precisam aceitar a inclusão nos serviços ofertados pela política pública de assistência social, nas açóes de incentivo à inclusão produtiva, além de garantir a frequência escolar de crianças e adolescentes que integram o núcleo familiar, e comprovar, quando necessário, a realização de atendimento pela rede municipal de saúde.

Art. $4^{\circ} \mathrm{O}$ programa tem como objetivos:

V - promover estratégias de qualificação profissional e inserção no mercado de trabalho através de oferecimento de cursos de qualificação profissional; e

VI - estimular a inserção dos beneficiários no mercado de trabalho por meio de encaminhamento ao trabalho assalariado, ao empreendedorismo, ao trabalho autônomo e ao trabalho associado no modelo da economia solidária. (Araraquara, 2019b).

A proposta de inclusão produtiva é realizada por meio de formações com o Sistema $S$, universidades ou OSC com recursos próprios do município ou parcerias, e são oferecidas no Espaço Kaparaó ou nos Cras. O Comitê do Bolsa Cidadania, órgão multisetorial formado pelas secretarias envolvidas no programa - de Assistência e Desenvolvimento Social; de Trabalho e Desenvolvimento Econômico; de Saúde; de Educação; e de Planejamento e Participação Popular -, é responsável pelo acompanhamento e pela fiscalização do programa. Foi formado também um comitê externo, composto por conselheiros de conselhos municipais, com o objetivo de fiscalizar a política pública.

\subsubsection{Programa Municipal de Economia Criativa e Solidária}

Tem como objetivos afirmar os fundamentos e a identidade da economia solidária enquanto estratégia e política de desenvolvimento econômico local e sustentável; fortalecer a organização social e política da economia solidária; ampliar e consolidar os EES; fomentar a economia criativa; e implementar as propostas deliberadas na I Conferência Municipal de Economia Criativa e Solidária para o período 2018-2021.

14. Cartão que pode ser utilizado no comércio local para aquisição de alimentos e produtos de higiene pessoal e de limpeza. 
Fruto do trabalho do Fórum Municipal de Economia Solidária e dos seus agentes - poder público, empreendimentos solidários, Universidade Estadual Paulista (Unesp) e OSCs -, foi elaborada uma carta de princípios, em 2008, que serviu de base para a criação da lei proposta pela vereadora Márcia Lia (PT), sendo promulgada como a Lei no 7.145/2009 (Araraquara, 2009).

Por meio da Incubadora Pública de Economia Criativa e Solidária (Ipecs) vinculada a Cetecs, com respaldo na Lei no 7.145/2019 e no Decreto no $12.338 / 2020,{ }^{15}$ são realizadas oficinas de sensibilização, formação em economia solidária e cooperativismo, apoio e assessoria técnica para EES (associaçôes, cooperativas e coletivos informais), bem como são fomentadas novas iniciativas e atores da economia solidária. Dados preliminares do Mapeamento dos Empreendimentos Econômicos Solidários, realizado em 2019 e atualizado em 2020 pela Cetecs e pelo Núcleo de Extensão e Pesquisa em Economia Solidária, Criativa e Cidadania da Faculdade de Ciências e Letras (Nepesc/FCL) da Unesp Araraquara, identificaram 22 EES no município.

Em relação ao fomento à economia criativa, pasta compartilhada com a Secretaria Municipal de Cultura de Araraquara e Fundação de Arte e Cultura do Município de Araraquara (Fundart), a Cetecs realiza um importante trabalho de incentivo e apoio às feiras de economia criativa e solidária e ao empreendedorismo em parceria com o Sebrae, além do oferecimento de qualificaçáo profissional e apoio à construção e à formalização de coletivos de cultura no modelo da economia solidária. Essa coordenadoria também trabalha com a organização dos trabalhadores ambulantes de alimentação para a participação em eventos municipais e vendas nos corredores comerciais da cidade.

Outro projeto importante na área criativa e de geração de renda é o Ecomagia, que acontece desde 2018 e consiste na criação de enfeites de Natal com material reciclável e decoração de espaços públicos com o resultado do trabalho. Este é desenvolvido por artesãs da cidade e também por mulheres de baixa renda, que são selecionadas para o projeto e aprendem uma nova profissão.

Além das feiras semanais e mensais, públicas ou de iniciativa de coletivos, a Cetecs garantiu, em 2019, um espaço da economia criativa e solidária na Feira Agrocomercial e Industrial da Região de Araraquara (Facira), possibilitando de forma gratuita espaço para venda e divulgação a trinta artesãos da cidade. Ademais, a Cetecs passou a realizar, também em 2019, a Feira do Território, que teve ediçóes até março de 2020 nos territórios de maior vulnerabilidade social do programa Territórios em Rede.

A Feira do Território, realizada em parceria com os Cras e com a comunidade local, tem o objetivo de fomentar o desenvolvimento local. Formada por tendas no meio de uma rua ou de um terreno público de grande circulação de pessoas, essa feira é um espaço para os empreendedores do bairro comercializarem seus produtos e também para que os moradores possam conhecer a diversidade de negócios realizados no próprio território, tais como: artesanato,

15. 0 decreto pode ser acessado na íntegra pelo portal: <https://bit.ly/3dnRMNl>. 
alimentação, produtos de limpeza, bazar de roupas e livros, divulgação de serviços, música e diversão no centro de bairros periféricos, cujo acesso à cultura ainda é restrito.

\subsubsection{Programa Novo Emprego e Programa Crédito para o seu Trabalho}

Ambos operados em parceria com o governo estadual, são desenvolvidos no Centro de Atendimento ao Trabalhador (Ceat), sede da Cetecs e também a porta de entrada para os demais programas e açóes. $\mathrm{O}$ Ceat tem passado por um processo de modernizaçáo com a criação de um sistema único de cadastro de programas e beneficiários; o desenvolvimento de aplicativos; e a utilização das redes sociais. O Posto de Atendimento ao Trabalhador (PAT), órgáo responsável por intermediação de emprego, emissão de carteira de trabalho e entrada no seguro-desemprego, realiza o trabalho majoritariamente por meio de e-mails e redes sociais.

O Projeto de Retorno e Ingresso ao Mercado de Trabalho - Programa Pró-Ação tem como finalidade orientar a população desempregada para o retorno ao mercado de trabalho, assim como a inserção de jovens em busca do primeiro emprego, por meio de palestras e workshops. Em 2017 e 2018, ele foi realizado nos Cras e atendeu mais de 120 pessoas em situação de vulnerabilidade social.

Faz parte também do Programa Novo Emprego, o Centro de Cultura Digital, um importante programa de inclusão digital e oferta de cursos da área de tecnologia da informação para jovens de baixa renda. Assim, foi realizada uma reestruturaçáo dos antigos telecentros, que estavam desativados, e foram disponibilizados espaços com computador e internet em áreas de vulnerabilidade social.

Em relação ao Programa Crédito para o seu Trabalho, o Banco do Povo Paulista opera com $90 \%$ do recurso do governo estadual, e o município é responsável por 10\% desse recurso mais os recursos humanos e físicos para o desenvolvimento do programa. Atualmente, passaram a ser operados também por esse banco dois programas do Sebrae: o Juro Zero e o Empreenda Rápido, que atendem pessoas jurídicas, produtores rurais, cooperativas e pessoas físicas com recursos que podem chegar a $\mathrm{R} \$ 50$ mil.

\subsection{Coordenadoria Executiva de Trabalho e de Economia Criativa e Solidária}

A partir do Plano Plurianual (PPA) 2018-2021, a Cetecs, alocada na SMTDE, além do PAT, do Banco do Povo Paulista e das pautas da economia criativa e economia solidária, incorporou em sua estrutura, a partir de 2018, a gestão dos programas de capacitaçáo profissional e cultura digital.

Nesse contexto, além da coordenadoria executiva, possui duas gerências, quatro unidades de gestão, quinze servidores públicos - agentes administrativos, agentes sociais, analista público, sociólogos, assistente social e psicólogo - e oito jovens cidadãos cursando técnico em informática, ciências sociais e economia. O programa Jovem Cidadão é o programa de estágio da Prefeitura Municipal de Araraquara para jovens de baixa renda que estejam nos ensinos médio, técnico ou superior. 


\section{TABELA 1}

\section{Cetecs (2020)}

\begin{tabular}{llcc}
\hline Gerências & Unidades de gestão & $\begin{array}{c}\text { Número de } \\
\text { servidores }\end{array}$ & $\begin{array}{c}\text { Número de jovens } \\
\text { cidadãos }^{1}\end{array}$ \\
\hline $\begin{array}{l}\text { Economia criativa e } \\
\text { solidária }\end{array}$ & Ceat & 6 & 2 \\
& Ipecs & 4 & 2 \\
Qualificação profissional & Espaço Kaparaó & 3 & 2 \\
\hline Total de servidores & Centro de Cultura Digital & 2 & $\mathbf{2}$ \\
\hline
\end{tabular}

Fonte: Coordenadoria de Recursos Humanos/Secretaria Municipal de Gestão e Finanças.

Elaboração dos autores.

Nota: ${ }^{1}$ O Programa Jovem Cidadão oferece oportunidades de aprimoramento e prática de conhecimentos teóricos, por meio de estágios supervisionados. As vagas são oferecidas na administração direta, indireta e em órgãos públicos conveniados com a prefeitura (disponível em: <https://tinyurl.com/y2go9qpz>).

Em 18 e 19 de novembro de 2019, foi realizado o curso de formação em economia solidária para gestores e servidores municipais. Oferecido pela Cetecs por meio de empresa especializada na área, o curso contou com todos os servidores e estagiários da coordenadoria, bem como com uma ampla rede de servidores das secretarias municipais: de Assistência e Desenvolvimento Social; de Planejamento e Participação Popular; de Gestão e Finanças; de Educação; de Saúde; de Cultura; de Comunicação e da própria SMTDE, totalizando mais de cinquenta servidores. A conclusão do curso foi a formação de uma rede municipal de gestores em economia solidária e o fortalecimento da temática nas políticas sociais transversais.

Referente ao orçamento público, podemos verificar que, de 2017 (PPA 2014-2017) para 2018 (PPA 2018-2021), houve um crescimento de 200\% do gasto público com a política de economia solidária. Importante também ressaltar que o orçamento da Cetecs representa cerca de $0,03 \%$ do orçamento público municipal e mais de $30 \%$ do orçamento da SMTDE, que possui outras três coordenadorias - de Agricultura; de Comércio e Turismo e Prestação de Serviços; e de Indústria e Tecnologia.

TABELA 2

Dotação orçamentária anual prevista da Cetecs de Araraquara (2016-2020) $(E m R \$)$

\begin{tabular}{lccccc}
\hline Ano & 2016 & 2017 & 2018 & 2019 & 2020 \\
\hline $\begin{array}{l}\text { Orçamento } \\
\text { anual }\end{array}$ & $517.733,00$ & $550.415,06$ & $1.664 .243,88$ & $1.798 .804,18$ & $1.917 .143,25$ \\
\hline
\end{tabular}

Fonte: Dados orçamentários da Secretaria Municipal de Planejamento e Participação Popular. Elaboração dos autores.

O orçamento da coordenadoria está dividido entre os quatro programas: i) Programa Municipal de Inclusão Social e Cidadania; ii) Programa Municipal de Economia Criativa e Solidária; iii) Programa Crédito para o seu Trabalho; e iv) Programa Novo Emprego. 


\subsection{Parcerias}

A FCL/Unesp Araraquara é a parceira histórica do poder público municipal da implementação de açôes e programas de economia solidária no município. Recentemente, as faculdades de farmácia, odontologia e química dessa universidade também estáo se engajando nas questóes da economia solidária.

O Programa Araraquara 2050, instituído pela Lei n⿳⺈ 9.500/2019, que consolida a parceria entre prefeitura e Unesp e visa promover um macroplanejamento estratégico do desenvolvimento do município, de curto, médio e longo prazo, respaldado no potencial econômico, ambiental e social, tem como um dos seus eixos principais as políticas públicas de economia solidária (Araraquara, 2019a).

Com atuação presente desde 2007, professores e pesquisadores dos cursos de administração pública e economia (re)formaram, em 2017, o Nepesc e participam do processo de incubação, formação, inscrição em editais, bem como de realização de pesquisas e produção de conteúdo, promovendo em parceria com o poder público encontros, seminários e congressos. Outras universidades, como o Instituto Federal de São Paulo (IFSP), campus de Araraquara, e a Universidade de Araraquara (Uniara), também são parceiras em projetos e açóes da economia solidária.

Algumas instituições do Sistema S, no caso, o Senac, o Sebrae e o Senai, também são parceiros da Cetecs. O Senai especificamente dá qualificação profissional; por sua vez, o Senac e o Sebrae passaram, a partir de 2018, a trabalhar ativamente as questóes relacionadas à economia solidária trazendo formaçóes, cursos e assessorias técnicas para auxílio e fomento do trabalho em grupo e da geração de renda de forma coletiva.

Firmou-se uma parceria internacional com a cidade de Torres Vedras, em Portugal, mediante acordo de cooperação técnica autorizado pela Lei no 9.406/2018, o qual contempla diversas áreas e tem como um dos seus eixos a economia solidária (Araraquara, 2018b).

\subsection{Congresso Internacional de Democracia Participativa: participação popular e economia solidária}

O I Congresso Internacional de Democracia Participativa: participação popular e economia solidária, organizado pela Prefeitura Municipal de Araraquara com apoio da Unesp, da Uniara, do Serviço Social do Comércio (Sesc) e do Conselho Latino-americano de Ciências Sociais (CLACSO), realizado entre 14 e 16 de março de 2019, no Centro Internacional de Convenção de Araraquara Dr. Nelson Barbieri, reuniu cerca de 1,3 mil interessados, entre lideranças populares, movimentos sociais, representantes de conselhos municipais, professores e estudantes universitários, dirigentes políticos, servidores públicos e representantes internacionais. Foram pessoas de 75 cidades diferentes e de quatro países (Brasil, Portugal, Bolívia e Argentina) que participaram do congresso, cujo objetivo foi promover o debate, a reflexão e a troca de experiências entre o poder público, as universidades e a sociedade.

$\mathrm{Na}$ conferência de abertura sobre democracia e economia solidária, ministrada pelo sociólogo Jessé de Souza e pelo economista e professor português Dr. Jorge de Sá (in memoriam), 
estiveram presentes mais de setecentas pessoas. $\mathrm{O}$ congresso foi finalizado com uma carta pela democracia com treze diretrizes para o fortalecimento da participação popular e da organização de trabalhadores(as) em cooperativas de economia solidária, entre outras questóes importantes. Ficou também definido que a segunda edição do encontro será realizada na cidade de Torres Vedras, em Portugal.

O debate sobre economia solidária foi grande, contando com a conferência de abertura do Dr. Jorge de Sá, A Economia Solidária como Estratégia de Desenvolvimento Social e Participação Popular, e a mesa-temática, A Economia Solidária como Estratégia de Desenvolvimento Social e Participação Popular, com as explanaçóes de Ana Umbelino, vereadora de Desenvolvimento Social, Cultura, Patrimônio Cultural e Turismo de Torres Vedras (Portugal); padre Vítor Melicias, coordenador do Centro Torrense de Estudos de Economia Social (Portugal); Sandro Pereira Silva, do Ipea; e Leandro Pereira Morais, coordenador do Nepesc/FCL/Unesp Araraquara e consultor da Organização Internacional do Trabalho (OIT).

O congresso internacional contou também com outras atividades referentes ao tema da economia solidária: posse do Conselho Municipal de Economia Criativa e Solidária; grupo de trabalho Possibilidades e Organização da Economia Social, Solidária e Criativa, coordenado pela Unesp e pela Universidade Federal de São Carlos (UFSCar); roda de conversa Mulheres na Economia Solidária, com a OSC SOF Sempreviva Organização Feminista; e mesa de movimentos sociais com diversas lideranças importantes do país, como o Movimento dos Trabalhadores Rurais Sem Terra (MST), o Movimento Nacional dos Catadores de Materiais Recicláveis (MNCR), a Central Única de Favelas (Cufa), a Frente de Luta por Moradia (FLM), o projeto Promotoras Legais Populares, entre outros movimentos sociais.

A reunião também abrangeu a realização concomitante da Feira Regional de Economia Solidária, Criativa e da Agricultura Familiar, com o propósito de gerar oportunidade de trabalho e renda e de fomentar a economia criativa e solidária na prática. Participaram cerca de 54 expositores de Araraquara e de outras cinco cidades. A feira organizada pela prefeitura de Araraquara contou com curadoria e apoio do Coletivo RolêFeira.

\section{EMPREENDIMENTOS E PARTICIPAÇÃO SOCIAL}

O Mapeamento dos Empreendimentos Econômicos Solidários realizado pela Cetecs e pelo Nepesc em 2019, por meio da realização das visitas aos EES, possibilitou a produção de um levantamento das principais características, demandas e dificuldades desses empreendimentos, bem como o aumento do conhecimento, por parte do poder público municipal, do cenário, da abrangência e da dinâmica de funcionamento da economia solidária no município de Araraquara e região, além da aproximação e do fortalecimento do diálogo entre os EES e a prefeitura.

Conforme atualização do mapeamento em 2020 e avaliação dos dados encontrados, podemos identificar 22 EES apoiados pelo poder público municipal, seja pela Cetecs, seja pela Coordenadoria Executiva de Agricultura, no caso dos empreendimentos rurais. Dentre os EES cadastrados estão: oito cooperativas, sete associaçóes e sete grupos ainda não formalizados. 
A maioria dos EES funciona em área urbana, somando 64\%, enquanto 36\% estão na área rural. Os beneficiários diretos somam 480 pessoas. As áreas de atuação são diversas - reciclagem, compostagem, agricultura familiar, alimentação, artesanato, construção civil, multisserviços e confecção - mostrando como a economia solidária é dinâmica. ${ }^{16}$

Dos EES mapeados no município, quatro cooperativas foram formalizadas em 2020 com beneficiários diretos dos programas de inclusão social e produtiva por meio do projeto O Cooperativismo como Porta para o Futuro, que prestou assessoria técnica para formaçáo e formalização das cooperativas. Dos sete grupos informais, quatro estão em processo de definiçóes para formalização, conforme o apêndice A.

Em termos de instituiçóes de deliberação participativa (IDP), ${ }^{17}$ a Lei no 9.143/2017 instituiu o Plano Municipal de Economia Criativa e Solidária, composto por dezenove diretrizes, para o período compreendido entre 2018 e 2021, e construído a partir das deliberaçóes da I Conferência Municipal de Economia Criativa e Solidária, realizada entre 14 e 15 de julho de 2017, com o tema Desenvolvimento Econômico Local com Trabalho Decente: geração de renda e inclusão social (Araraquara, 2017b). ${ }^{18}$

Já em 2018 foi criado o Conselho Municipal de Economia Criativa Solidária, por meio da Lei no 9.410/2018. O conselho é responsável, entre outras coisas, pelo apoio e pela fiscalização da implementação do Plano Municipal de Economia Criativa e Solidária (Araraquara, 2018c). Com formação paritária entre poder público, entidades de apoio e fomento e empreendimentos, ele se reúne mensalmente para debater, refletir e propor ideias e açôes, assim como é o ambiente das principais deliberaçóes e prestação de contas da Cetecs. Vale reforçar que essa coordenadoria também participa dos principais conselhos formados pelo poder público e pela sociedade civil em Araraquara, bem como podemos encontrar a proposição de açôes de geração de trabalho e renda por meio da economia solidária em quase todos os planos municipais setoriais oriundos das conferências municipais.

\section{ENFRENTAMENTO À PANDEMIA DA COVID-19}

Araraquara se destaca no cenário nacional por suas açóes de combate ao coronavírus. Há um conjunto de açóes que leva a cidade a ter o menor índice de letalidade do estado de São Paulo e um dos menores do Brasil, entre as quais estão: criação precoce do Comitê de Contingência do Coronavírus; estruturação do centro de referência do coronavírus; construção do hospital de campanha; política ampla de testagem e diagnóstico, com apoio dos laboratórios da Unesp e da Uniara; equipes de bloqueio e monitoramento de infectados; a criação de uma rede de solidariedade, entre outras.

16. Para uma análise dos dados do Mapeamento de Economia Solidária no nível nacional, ver Silva (2017a).

17. Sobre o conceito de IDP, ver Silva (2018). Para conferir experiências de IDP em economia solidária, ver Alencar e Silva (2013) e Silva, Cunha e Silva (2018).

18. A I Conferência Municipal de Economia Criativa e Solidária contou com a presença de 143 pessoas entre EES, universidades, entidades de fomento e poder público municipal. 
A Rede de Solidariedade de Araraquara se tornou uma forte aliada no combate à fome e na possibilidade de apoio às famílias e às pessoas que mais estão sofrendo com a pandemia da Covid-19. No âmbito da produção de trabalho, foi criado o programa Araraquara contra o Coronavírus, que conta com apoiadores de combate ao coronavírus, possibilitando a contratação emergencial e temporária de pessoas socialmente vulneráveis para a execução de serviços de limpeza e obras emergenciais. Esse feito ajudou na geração de renda para mais de uma centena de famílias que estavam passando necessidade.

A economia solidária se modernizou em reuniôes virtuais ou presenciais apenas com as lideranças para que o processo em curso não sucumbisse. Foi possível formalizar as cooperativas que estavam em processo de formação ${ }^{19}$ e iniciar uma nova trajetória de inserção no mercado para a efetiva geração de renda, assim como apoiar os catadores da Cooperativa Acácia para não pararem os serviços de coleta seletiva e os demais grupos.

A prefeitura de Araraquara adquiriu 15 mil máscaras confeccionadas no modelo da economia solidária por meio da Associação Mãos que Criam, em parceria com o Nepesc/Unesp, gerando renda direta a quinze mulheres responsáveis economicamente por suas famílias. ${ }^{20}$ As máscaras foram distribuídas a pessoas de baixa renda por meio da Rede de Solidariedade de Araraquara, dos Cras, da guarda municipal e dos agentes de vigilância e segurança pública.

\section{CONSIDERAÇÕES FINAIS}

A Cetecs tornou-se um setor dinâmico dentro da Prefeitura Municipal de Araraquara. Uma coordenadoria que trabalha de forma intersetorial e com variadas parcerias e que criou uma cultura participativa de trabalho dentro da gestão pública. $\mathrm{O}$ beneficiário recebe uma atenção integral na Cetecs, onde ele é acolhido em sua vulnerabilidade, e segue uma trajetória com portas abertas para a construção de um futuro coletivo e solidário, com reinserção social e produtiva.

Os principais desafios são também o foco da Cetecs para os projetos futuros: a consolidação de uma rede de empreendimentos e arranjos produtivos locais, a criação de um banco comunitário com moeda social na perspectiva do desenvolvimento local, a implantação do Centro de Comércio Justo e Solidário e do Centro de Economia Solidária e Saúde Mental e a manutenção e sustentabilidade dos EES.

Estamos conscientes de que a economia solidária é uma importante estratégia de combate à fome, ao desemprego e à crise econômica, capaz de propor um novo modelo de superação das mazelas sociais, por meio do trabalho cooperado, da autogestáo dos trabalhadores, da valorização do ser humano e da formação de redes de solidariedade e proteção social.

19. Conforme mencionado anteriormente, foram formalizadas quatro novas cooperativas com apoio da Cetecs no primeiro semestre de 2020: Cooperativa de Trabalho em Serviços Gerais - Vitória Multiserviços; Cooperativa de Trabalho e Serviços de Alimentação Panelas Unidas; Cooperativa dos Trabalhadores da Construção Civil de Araraquara - Coopermorada; e Cooperativa Social de Trabalho em Recuperação de Materiais dos Egressos Prisionais de Araraquara Sol Nascente.

20. Para mais informações sobre essa experiência, ver Silva et al. (2020). 


\section{REFERÊNCIAS}

ALENCAR, J. L. O.; SILVA, S. P. Participação social em políticas públicas de economia solidária: o que dizem os membros do Conselho Nacional de Economia Solidária? Mercado de Trabalho: conjuntura e análise, v. 18, n. 54, p. 93-100, 2013.

ARARAQUARA. Lei no 7.145, de 27 de novembro de 2009. Instituiu o Programa de Trabalho e Economia Social e Solidária, estabelece princípios fundamentais e objetivos da Política Municipal de Trabalho e Economia Solidária no Município; e dá outras providências. Folha da Cidade, n. 7.271, 15 dez. 2009. Disponível em: <https://bit.ly/34qqjGW>. Acesso em: 5 out. 2020.

. Lei no 8.998, de 19 de junho de 2017. Cria o Programa de Incentivo à Inclusão Social (PIIS); e dá outras providências. A Cidade, ano 112, n. 148, 22 jun. 2017a. Disponível em: <https://bit.ly/2SvSu1s>. Acesso em: 5 out. 2020.

Lei n 9.143, de 30 de novembro de 2017. Institui o Plano Municipal de Economia Criativa e Solidária e dá outras providências. A Cidade, 1ํodez. 2017b. Disponível em: <https:// bit.ly/3d1Gcrj>. Acesso em: 5 out. 2020.

. Lei no 9.344, de 15 de agosto de 2018. Institui o Programa Municipal Territórios em Rede e dá outras providências. A Cidade, n. 184, 22 ago. 2018a. Disponível em: <https://bit. ly/3cYo81d>. Acesso em: 5 out. 2020.

Lei n⿳9 9.406, de 31 de outubro de 2018. Autoriza a celebração de acordo de cooperação técnica com o Município de Torres Vedras, em Portugal, em diversas áreas. Folha da Cidade, n. 9893, 7 nov. 2018b. Disponível em: <https://bit.ly/2GxW0Ga>. Acesso em: 5 out. 2020.

. Lei no 9.410, de 7 novembro de 2018. Dispóe sobre a criação do Conselho Municipal de Economia Criativa Solidária e dá outras providências. A Cidade, 8 nov. 2018c. Disponível em: <https://bit.ly/3d4EsNO>. Acesso em: 5 out. 2020.

Lei n⿳⺈ 9.500, de 15 de março de 2019. Institui o Programa Araraquara 2050 e dá outras providências. A Cidade, 16 mar. 2019a. Disponível em: <https://bit.ly/3needZY>. Acesso em: 5 out. 2020.

Lei no 9.585, de 23 de maio de 2019. Institui o Programa Municipal de Combate à Fome e Incentivo à Inclusão Produtiva (Bolsa Cidadania); e dá outras providências. A Cidade, 24 maio 2019b. Disponível em: <https://bit.ly/3l7TAgi>. Acesso em: 5 out. 2020.

BRASIL. Lei $\mathrm{n}^{-} \mathbf{1 1 . 4 4 5}$, de 5 de janeiro de 2007. Estabelece diretrizes nacionais para o saneamento básico; altera as leis nํㅗ 6.766 , de 19 de dezembro de 1979, 8.036, de 11 de maio de 1990, 8.666, de 21 de junho de 1993, 8.987, de 13 de fevereiro de 1995; e dá outras providências. Diário Oficial da Uniáo, Brasília, 8 jan. 2007. Disponível em: <https://bit. ly/36yTVVi>.Acesso em: 5 out. 2020.

MORAIS, L.; BACIC, M. Social and solidarity economy and the need for its entrepreneuring ecosystem: current challenges in Brazil. Revista de Economía Pública, Social y Cooperativa, n. $98,2020$.

MNCR - MOVIMENTO NACIONAL DOS CATADORES DE MATERIAIS RECICLÁVEIS. Cooperativa Acácia completa 18 anos de resistência em Araraquara. MNCR.org, 19 nov. 2011. Disponível em: <https://tinyurl.com/yxztj8ex>. Acesso em: 2 dez. 2020. 
PAIVA, C. C. Mulheres catadoras: articulação política e ressignificação social através do trabalho. Revista Ideias, v. 7, n. 2, p. 151-174, 2016.

SANCHES, C. C.; MORAIS, L. P. Economia solidária e o ecossistema empreendedor solidário: o caso de Araraquara (SP). Mercado de Trabalho: conjuntura e análise, v. 26, n. 68, 2020.

SILVA, S. P. Análise das dimensóes socioestruturais dos empreendimentos de economia solidária no Brasil. Brasília: Ipea, 2017a. (Texto para Discussão, n. 2271).

Organizaçáo coletiva de catadores de material reciclado no Brasil: dilemas e potencialidades sob a ótica da economia solidária. Brasília: Ipea, 2017b. (Texto para Discussão, n. 2268).

Democracia, políticas públicas e instituiçóes de deliberação participativa. Brasília: Ipea, 2018. (Texto para Discussão, n. 2358).

A política de economia solidária no ciclo orçamentário nacional (2004-2018): inserção, expansão e crise de paradigma. Brasília: Ipea, 2019. (Texto para Discussão, n. 2434).

SILVA, S. P.; CUNHA, G. C.; SILVA, R. F. Mobilizaçáo social e deliberação participativa na formaçáo da agenda governamental: uma análise processual das Conferências Nacionais de Economia Solidária. Rio de Janeiro: Ipea, 2018. (Texto para Discussão, n. 2360).

SILVA, S. P. et al. Extensão universitária, economia solidária e geração de oportunidades no contexto da Covid-19: uma visão a partir de três experiências concretas no território brasileiro. Mercado de Trabalho: conjuntura e análise, v. 26, n. 69, 2020.

STROZZI, W. Com aprovação do Bolsa Cidadania, saiba de onde sairão os recursos para implantação. ACidadeON, 23 maio 2019. Disponível em: <https://tinyurl.com/y2lwjlcd>. Acesso em: 2 dez. 2020.

\section{BIBLIOGRAFIA COMPLEMENTAR}

CAPACLE, C. A política social de economia solidária: um estudo de caso do município de São Carlos. 2010. Dissertação (Mestrado) - Universidade Federal de São Carlos, São Carlos, 2010.

. As relíquias do lixão: mulheres catadoras e o engenhoso trabalho de cooperar e resistir. 2017. Tese (Doutorado) - Universidade Estadual de Campinas, Instituto de Filosofia e Ciências Humanas, Campinas, 2017. 269 p.

SILVA, S. P. Dimensôes analíticas do conceito de inclusão produtiva para fins de política social: uma revisão bibliométrica. Mercado de Trabalho: conjuntura e análise, v. 26, n. 68, 2020. 


\section{APÊNDICE A}

\section{TABELA A. 1 \\ Cadastro de empreendimentos econômicos solidários (EES) do município de Araraquara/São Paulo}

\begin{tabular}{|c|c|c|c|}
\hline $\begin{array}{l}\text { Forma de } \\
\text { organização }\end{array}$ & Área de localização & Nome da organização & Total \\
\hline \multirow{7}{*}{ Associações } & \multirow{4}{*}{ Rural } & $\begin{array}{l}\text { Associação de Mulheres Assentadas do Assentamento Monte Alegre } \\
\text { Seis (AMA) }\end{array}$ & \multirow{7}{*}{7} \\
\hline & & $\begin{array}{l}\text { Associação de Mulheres da Agricultura Familiar e da Luta Camponesa } \\
\text { de Araraquara e Região (AMCA) }\end{array}$ & \\
\hline & & Associação Chico Bento do Assentamento Bela Vista & \\
\hline & & $\begin{array}{l}\text { Associação dos Agricultores Familiares Produtores de Mandioca da } \\
\text { Região de Araraquara, Bauru e São Carlos (Associação Macaxeira) }\end{array}$ & \\
\hline & \multirow{3}{*}{ Urbana } & Horta Comunitária da Zona Norte de Araraquara & \\
\hline & & $\begin{array}{l}\text { Associação de Inclusão e Defesa dos Cidadãos nos Meios Socioeconô- } \\
\text { micos Mãos que Criam (Associação Mãos que Criam) }\end{array}$ & \\
\hline & & $\begin{array}{l}\text { Associação dos Trabalhadores do Comércio Alternativo de Araraquara } \\
\text { (ATCAAR) }\end{array}$ & \\
\hline \multirow{8}{*}{ Cooperativas } & \multirow{3}{*}{ Rural } & $\begin{array}{l}\text { Cooperativa Agropecuária Mista do Assentamento Bela Vista do } \\
\text { Chibarro (Coobela) }\end{array}$ & \multirow{8}{*}{8} \\
\hline & & Cooperativa dos Produtores Agrícolas de Motuca e Região (Coopam) & \\
\hline & & $\begin{array}{l}\text { Cooperativa dos Agricultores Familiares de Araraquara e Região Mora- } \\
\text { da do Sol (Coopersol) }\end{array}$ & \\
\hline & \multirow{5}{*}{ Urbana } & $\begin{array}{l}\text { Cooperativa Acácia de Catadores, Coleta, Triagem e Beneficiamento de } \\
\text { Materiais Recicláveis de Araraquara (Cooperativa Acácia) }\end{array}$ & \\
\hline & & $\begin{array}{l}\text { Cooperativa dos Trabalhadores da Construção Civil de Araraquara - } \\
\text { Coopermorada }\end{array}$ & \\
\hline & & Cooperativa de Trabalho em Serviços Gerais - Vitória Multiserviços & \\
\hline & & Cooperativa de Trabalho e Serviços de Alimentação Panelas Unidas & \\
\hline & & $\begin{array}{l}\text { Cooperativa Social de Trabalho em Recuperação de Materiais dos } \\
\text { Egressos Prisionais de Araraquara Sol Nascente }\end{array}$ & \\
\hline \multirow{7}{*}{$\begin{array}{l}\text { Grupos } \\
\text { informais }\end{array}$} & \multirow[t]{3}{*}{ Rural } & Fuxico do Bem - Grupo de Artesanato do Assentamento Bela Vista & \multirow{7}{*}{7} \\
\hline & & Luz do Valle & \\
\hline & & Quilombo Rosa & \\
\hline & \multirow{4}{*}{ Urbana } & Coletivo RolêFeira & \\
\hline & & Mulheres Criativas & \\
\hline & & Mulheres do Jardim Hortênsias & \\
\hline & & Mulheres Costureiras do Selmi Dei & \\
\hline Total & & & 22 \\
\hline
\end{tabular}

Fonte: Dados preliminares do Mapeamento dos EES de Araraquara - Coordenadoria Executiva de Trabalho e de Economia Criativa e Solidária (Cetecs) e Núcleo de Extensão e Pesquisa em Economia Solidária, Criativa e Cidadania da Faculdade de Ciências e Letras da Universidade Estadual Paulista (Nepesc/FCL/Unesp).

Elaboração dos autores. 